\title{
PPARs in the Renal Regulation of Systemic Blood Pressure
}

\author{
Tamás Rőszer and Mercedes Ricote \\ Department of Regenerative Cardiology, Spanish National Cardiovascular Research Center (CNIC), 28029 Madrid, Spain
}

Correspondence should be addressed to Tamás Rőszer, troszer@cnic.es and Mercedes Ricote, mricote@cnic.es

Received 23 September 2009; Revised 24 February 2010; Accepted 31 March 2010

Academic Editor: Tianxin Yang

Copyright ( $\odot 2010$ T. Rőszer and M. Ricote. This is an open access article distributed under the Creative Commons Attribution License, which permits unrestricted use, distribution, and reproduction in any medium, provided the original work is properly cited.

\begin{abstract}
Recent research has revealed roles for the peroxisome proliferator activated receptor (PPAR) family of transcription factors in blood pressure regulation, expanding the possible therapeutic use of PPAR ligands. PPAR $\alpha$ and PPAR $\gamma$ modulate the renin-angiotensinaldosterone system (RAAS), a major regulator of systemic blood pressure and interstitial fluid volume by transcriptional control of renin, angiotensinogen, angiotensin converting enzyme (ACE) and angiotensin II receptor 1 (AT-R1). Blockade of RAAS is an important therapeutic target in hypertension management and attenuates microvascular damage, glomerular inflammation and left ventricular hypertrophy in hypertensive patients and also show antidiabetic effects. The mechanisms underlying the benefits of RAAS inhibition appear to involve PPAR $\gamma$-regulated pathways. This review summarizes current knowledge on the role of PPARs in the transcriptional control of the RAAS and the possible use of PPAR ligands in the treatment of RAAS dependent hypertension.
\end{abstract}

\section{Introduction}

Peroxisome proliferator activated receptors (PPARs), members of the superfamily of ligand regulated transcription factors, are expressed in the cardiovascular system and control diverse vascular functions by mediating appropriate changes to gene expression (reviewed by $[1,2]$ ). $\operatorname{PPAR} \alpha$, $\operatorname{PPAR} \beta / \delta$ and PPAR $\gamma$ isoforms are expressed in endothelial cells, while vascular smooth muscle cells (VSMCs) express only $\operatorname{PPAR} \alpha$ and $\operatorname{PPAR} \gamma[1,3] . \operatorname{PPAR} \alpha$ and $\operatorname{PPAR} \beta / \delta$ affect the vasculature through several mechanisms, including regulation of endothelial function, VSMC apoptosis, and antiinflammatory properties via the control of cytokine signaling and the downregulation of inflammatory cytokine induced genes $[1,2,4]$. Moreover, PPAR gene mutations lead to disturbances in blood pressure regulation. In humans, both the Pro12Ala polymorphism and mutations in the PPAR $\gamma$ gene contribute to hypertension $[5,6]$. Mice lacking PPAR $\gamma$ in VSMCs or endothelial cells show altered arterial vasoconstriction [7], while $\operatorname{PPAR} \alpha$ knockout mice develop salt-sensitive hypertension [8]. Fibrates, agonists of $\operatorname{PPAR} \alpha$, and thiazolidinediones (TZDs), ligands for PPAR $\gamma$ have cholesterol- and triglyceride-lowering effects and are insulin sensitizers, with additional antiinflammatory and antiatherogenic benefits $[9,10]$. These drugs are primarily used in the treatment of lipid homeostasis disorders, type 2 diabetes mellitus and atherosclerosis $[1,2]$. Hypertension is a common comorbidity of atherosclerosis and insulin resistance and clinical observations show that TZDs effectively reduce blood pressure in type 2 diabetic patients [10-19]. TZDs also reduce peripheral resistance in several experimental models of hypertension leading to reduced blood pressure [20]. The antihypertensive effects of TZDs are mediated by the vascular endothelia $[20,21]$ and through an inhibitory action on VSMC L-type $\mathrm{Ca}^{2+}$-channels [9]. Endothelial function in hypertension is also improved by fibrates, and these compounds can reduce blood pressure in patients with hypertriglyceridemia [22]. Recent studies indicate that PPAR $\gamma$-regulated gene expression can also influence the function of the renin-angiotensin-aldosterone system (RAAS), thus allowing PPAR $\gamma$ ligands to alter vascular tone and total body fluid volume [13-15, 23]. An involvement of PPAR $\alpha$ in the modulation of the RAAS has also been proposed, although its relevance to systemic blood pressure regulation is still disputed $[10,19,24]$.

The RAAS is a cascade formed by hormone-like substances released from the kidney and the adrenal gland, and acts as a long-term regulator of systemic blood pressure 
and interstitial fluid volume (reviewed by [25]). The most potent effector molecule of the RAAS is angiotensin II (Ang II), which elevates systemic blood pressure through the constriction of blood vessels and furthermore enhances aldosterone secretion, catecholamine release, sympathetic nerve activity and myocardial contractility (Figure 1). Aldosterone, the other effector molecule of the RAAS, contributes to the maintenance of fluid homeostasis and blood volume through the regulation of the sodium and water resorbtion capacity of the kidneys and the intestinal epithelium [25]. Aldosterone and Ang II can also act as paracrine factors, and influence inflammation, mitogenesis, apoptosis and cell growth, through which they contribute not only to the development of hypertension but also to its cardiovascular complications $[16,25-31]$, such as microvascular damage, glomerular inflammation, podocyte injury and left ventricular hypertrophy $[32,33]$. A major medication strategy for RAAS-dependent hypertension is therefore to block steps in the RAAS cascade, thereby lowering systemic blood pressure and reducing associated cardiovascular complications [25].

Newly identified roles of PPAR $\gamma$ and PPAR $\alpha$ in the modulation of blood pressure have already begun to expand the potential therapeutic uses of PPAR $\gamma$ and PPAR $\alpha$ ligands $[15,21]$. However, the role of $\operatorname{PPAR} \alpha$ in the regulation of the RAAS is disputed [10], and unwanted hepatotoxic and cardiac effects of currently available PPAR $\gamma$ ligands [34, 35] limit the use of these drugs in hypertension management. A critical review of molecular mechanisms and physiological consequences of PPAR activity in the RAAS is therefore timely. In this review we summarize current knowledge about the role of PPAR $\gamma$ and PPAR $\alpha$ in the functioning of the RAAS and discuss the possible modulation of RAASdependent hypertension by these transcription factors at the level of gene expression.

\section{PPAR Ligands and Mechanism of Action}

The three different PPAR subtypes (PPAR $\alpha$ [NR1C1], $\mathrm{PPAR} \beta / \delta$ [NRC2] and PPAR $\gamma$ [NRC3]) have different tissue distribution and are involved in distinct biological processes. $\operatorname{PPAR} \alpha$ is highly expressed in liver, heart, kidney cortex and skeletal muscle; PPAR $\beta / \delta$ is abundantly expressed throughout the body; and PPAR $\gamma$ is predominantly expressed in adipose tissue, liver, kidney, skeletal muscle, monocytes and macrophages [2]. PPARs, as ligand regulated transcription factors, can modulate gene expression through binding to hormone response elements in the promoter or enhancer sequences of target genes $[1,2]$. The domain strucure of PPARs is similar to that of other nuclear receptors. A ligandindependent transactivation amino-terminal domain is followed by a DNA-binding domain (DBD) that contains zinc finger motifs. The ligand binding domain (LBD) is located at the carboxy terminus and is composed of several $\alpha$ helices that form a hydrophobic ligand-binding pocket. The DBD mediates PPAR binding to PPAR response elements (PPREs) within the promoters of target genes. For DNA binding, PPARs must dimerize with another nuclear receptor, the retinoid X receptor (RXR). Heterodimers of PPARs and RXR bind to PPREs and then activate expression of gene networks involved in the control of lipid and carbohydrate metabolism in several cell types. In addition, PPARs can also transrepress proinflammatory genes by antagonizing the activities of other transcription factors such as members of the nuclear factor $-\kappa \mathrm{B}(\mathrm{NF}-\kappa \mathrm{B})$ and activator protein-1 (AP-1) families. Several lipid mediators and a variety of molecules that are derived from fatty acid metabolism are natural ligands of PPARs. In the last decade, much attention has focused on the pharmacological modulation of PPARs. For example, fibrates (clofibrate, fenofibrate, bezafibrate) are activators of $\operatorname{PPAR} \alpha$, that are used in the treatment of hyeprlipidemias, and synthetic $\operatorname{PPAR} \beta / \delta$ activators can improve insulin sensitivity and increase fatty acid catabolism. TZDs, synthetic ligands of $\operatorname{PPAR} \gamma$, such as rosiglitazone and pioglitazone, have already been introduced into clinical practice for the treatment of insulin resistance $[1,2]$. However, animal studies with chronic TZD treatment $[34,35]$ and four large trials of TZDs with cardiovascular endpoints have also revealed some unwanted effects of TZDs, such as fluid retention and heart failure [34]. Today there is therefore increased interest in the identification of selective PPAR modulators (SPPARMs) to improve metabolic and antiinflammatory benefits of PPAR activation [36].

\section{Renin Production Is Influenced by PPAR $\gamma$ Ligands}

Cells of the juxtaglomerular apparatus (JGA) express PPAR $\gamma$ [37]. The JGA produces renin, a $43 \mathrm{kDa}$ protease (EC 3.4.99.19, new EC 3.4.23.15) that cleaves angiotensinogen (AGT) to yield angiotensin I (Ang I). Signals that promote renin synthesis and secretion can lead to RAAS-dependent hypertension in humans [25]. Overproduction of renin can result from enhanced renin gene transcription, as occurs in spontaneously hypertensive rats, which have mutations in the transcription factor binding sites of the renin gene [38].

Endogenous and pharmacological PPAR $\gamma$ agonists, such as unsaturated fatty acids and TZDs, have been shown to stimulate renin gene expression in renin producing cells, such as cultured JGA cells [37] (Figure 2). The hunan renin gene contains two PPAR $\gamma$ binding sequences $[37,39]$ and knockdown of PPAR $\gamma$ increases PPRE-driven renin transcription in vitro. JGA specific deletion of PPAR $\gamma$ in mice results in upregulated renin transcription [40].

Although PPAR $\gamma$ controls renin gene transcription, potential therapeutical benefits of PPAR $\gamma$ ligand mediated changes in renin expression have yet to be evaluated.

\section{PPAR $\alpha$ and PPAR $\gamma$ Regulate Angiotensinogen Gene Expression}

Angiotensionogen (AGT), the first substrate of the RAAS, is an $\alpha_{2}$-glycoprotein and present at nanomolar concentrations in serum $[25,41]$. Cleavage by renin yields the decapeptide Ang I, which is then converted by angiotensin converting enzyme (ACE; EC 3.4.15.1) to the active octapeptide Ang II (Figure 1). Ang II can induce arteriolar constriction 


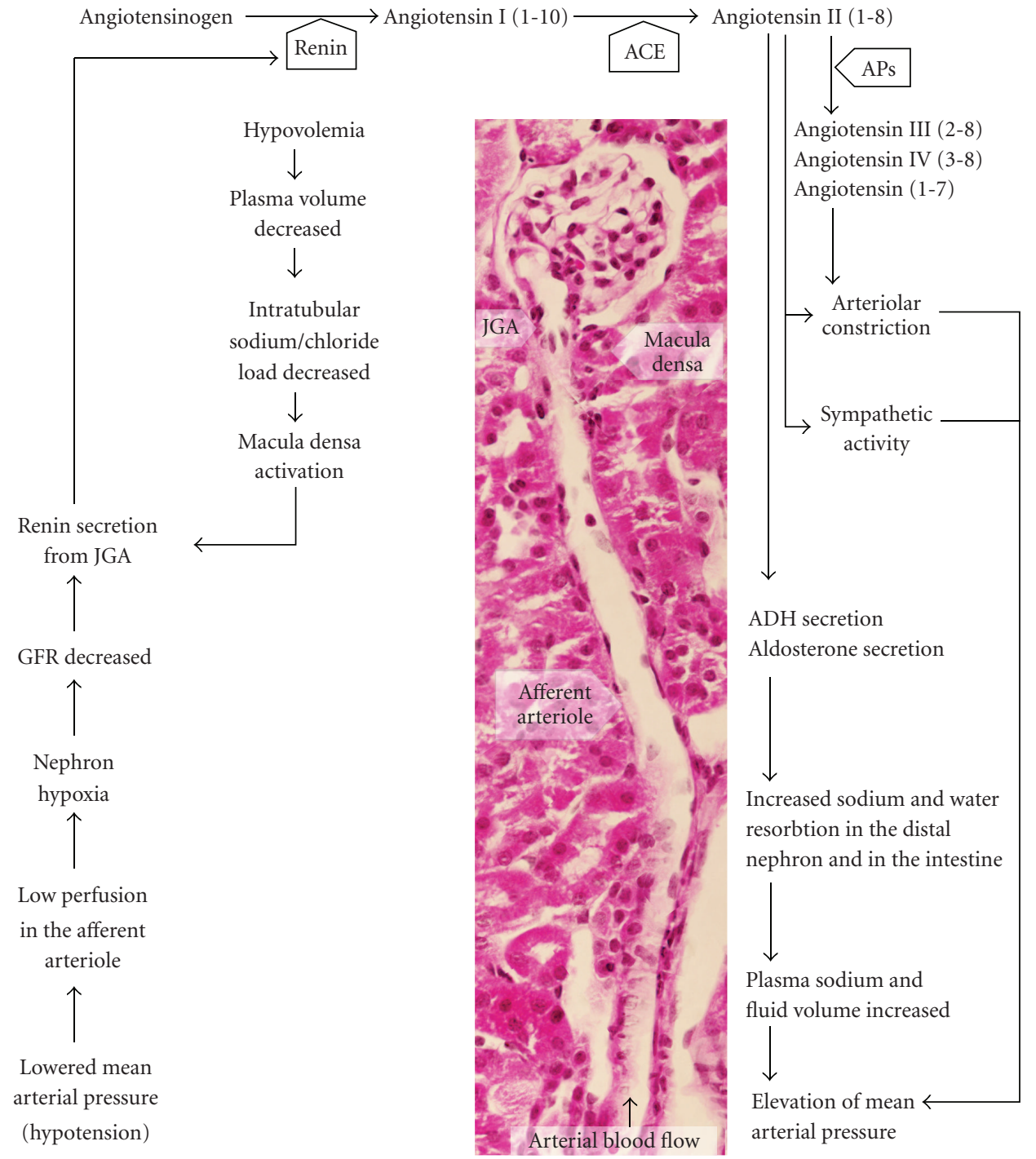

FIGURE 1: Schematic representation of the RAAS cascade. The main signals activating the RAAS are the reduced nephron perfusion due to lowered arterial mean pressure and the hypovolemia-induced decrease in intratubular sodium/chloride load. Kidney JGA cells produce renin, which activates the RAAS cascade, yielding two main effector molecules, angiotensin II (AngII) and aldosterone. Other vasoactive angiotensins can also be produced from Ang-II by the action of different aminopeptidases (APs). The main ouputs of RAAS activation are arteriolar vasoconstriction and fluid retention, which both elevate mean arterial blood pressure. PPAR $\gamma$ is expressed in JGA, the source of renin and in the distal collecting ducts, targets of aldosterone. Histological image shows a renal glomerule with the longitudnal section of the afferent arteriole in mouse kidney (hematoxylin-eosin staining, N: 400x).

and consequently elevate systemic vascular tone and blood pressure [25].

Elevated serum levels of AGT are often recognized as the cause of hypertension, because higher AGT concentrations lead to supernormal Ang II production [25]. Under physiological conditions, AGT is mainly synthesized in the liver, although adipocytes can also liberate physiologically relevant amounts of AGT [25-27]. In humans, hepatic AGT mRNA levels correlate positively with plasma AGT concentration $[41,42]$. The human T235 allelic variant of the AGT gene is associated with enhanced hepatic AGT mRNA synthesis, higher serum AGT levels, and consequent hypertension [42]. Injection of antisense oligonucleotides against AGT into rats results in a transient fall in blood pressure accompanied by decreased levels of plasma AGT and liver AGT mRNA [43]. These data show that AGT production is tightly regulated at the level of gene expression.

The human AGT promoter is activated by PPAR $\alpha / \mathrm{RXR}$ heterodimers and is also bound by hepatocyte nuclear factor 4 (HNF-4), another member of the nuclear receptor family [24]. The PPAR $\alpha$ response region in the AGT promoter includes a binding site for HNF-4, composed of two core motifs ( $\mathrm{RG}(\mathrm{G} / \mathrm{T}) \mathrm{TCA}$ or a closely related sequence) separated by a single nucleotide (DR1 element). The PPAR $\alpha$ ligand bezafibrate can activate the human AGT promoter in HeLa cells, which do not express HNF-4, but this 


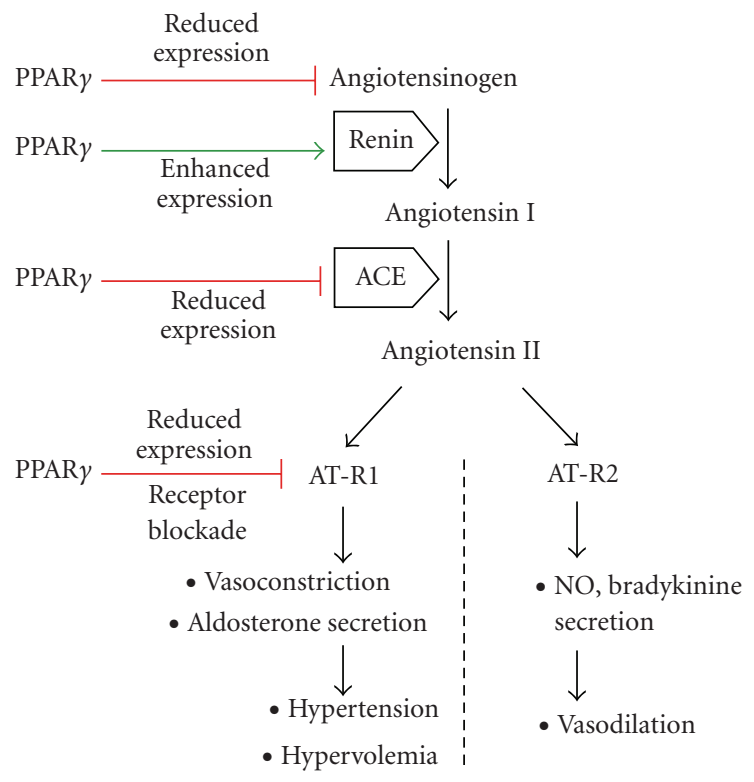

FIGURE 2: Role of PPAR $y$ in the modulation of the RAAS cascade. Gene expression of RAAS molecules is modulated by PPAR $\gamma$. Although renin production is facilitated by PPAR $\gamma$ activation, the hypertensive effects of RAAS activation are attenuated by PPAR $\gamma$ ligands, since these strongly reduce Ang II levels, ACE and AT-R1 gene expression. Telmisartan also exerts AT-R1 blocking properties. Simultaneously with blockade of AT-R1, the beneficial vasodilator effects of AT-R2 activation become dominant.

effect is not seen in HNF-4-expressing cell lines, such as HepG2 cells or HNF-4-transfected HeLa cells, indicating that HNF-4 interferes with promoter binding by PPAR $\alpha / \mathrm{RXR}$ heterodimers [24]. These data suggest that AGT promoter activity can be enhanced by nuclear receptor signaling via $\operatorname{PPAR} \alpha$ and RXR, predisposing to hypertension.

In severe obesity, adipose tissue can be an important source of AGT, potentially contributing to the development of hypertension and the vascular complications of metabolic syndrome [26-29] (Figure 3). This idea is supported by work with a dominant negative $\mathrm{P} 467 \mathrm{~L}$ mutation in the ligand-binding domain of PPAR $\gamma$. In humans the P467L mutation is associated with severe insulin resistance and hypertension [44] and homozygous mice with the equivalent P465L mutation die in utero [44]. Heterozygous mice are hypertensive and show increased gene expression of AGT in subcutaneous adipose tissue. Increased AGT production by white adipose tissue in this mouse model not only induces hypertension; it also increases lipogenic gene expression, leading to abnormal fat distribution [44]. The PPAR $\gamma$ ligand rosiglitazone, however, has no effect on AGT expression in human adipocytes, and an action of PPAR $\gamma$ on adipocyte AGT gene regulation in humans has not been demonstrated [45].

\section{PPAR $\gamma$ and PPAR $\alpha$ Modulate Expression of Angiotensin Converting Enzyme}

Inhibition of ACE results in decreased production of Ang II and decreased metabolism of bradykinin, leading to systemic dilation of blood vessels and a decrease in arterial blood pressure [46]. Moreover, Ang II-induced aldosterone secretion is also reduced, leading to decreased water and sodium reabsorption and a reduction in extracellular fluid volume $[25,46]$.

Ligands of PPAR $\alpha$ and PPAR $\gamma$ can suppress the gene expression of ACE in vascular tissues [13, 47, 48] (Figure 2). In streptozotocin-induced diabetes in rats, the PPAR $\alpha$ agonist bezafibrate and the PPAR $\gamma$ ligand pioglitazone can equally protect against the streptozotocin-induced upregulation of ACE in the aortic wall. This action of PPARs promotes beneficial antiatherogenic effects under insulin resistant conditions [13]. Similarly, ACE gene expression in obese Zucker rats is reduced by chronic treatment with rosiglitazone [47]; and clinical studies have demonstrated that the partial PPAR $\gamma$ agonist telmisartan inhibits ACE and blocks Ang II receptor type 1 (AT-R1) [36, 49]. This combined ACE suppressing and Ang II receptor blocking (ARB) effect strengthens the vascular protection conferred to hypertensive type 2 diabetic patients by the antiinflammatory and antiatherogenic consequences of PPAR $\gamma$ activation $[36,46]$ (Figure 2).

In contrast, antihypertensive effect of fibrates is controversial, since although these compounds reduce blood pressure in patients with hypertriglyceridemia [22], they have the opposite effect in glucocorticoid-induced diabetes [50]. The existence of antihypertensive and antiatherogenic actions of $\operatorname{PPAR} \alpha$ are also challenged by work with the Tsukuba hypertensive mouse (THM), a model of Ang IIinduced hypertension [19]. In the THM system, transgenic expression of the entire human RAAS leads to high Ang II and aldosterone levels, causing hypertension and atherosclerosis. In PPAR $\alpha$-deficient THM animals this hypertension is totally abolished [19], and this is accompanied by a reduction in plasma renin and by a normalization of serum aldosterone. PPAR $\alpha$-deficient THM animals also fail to develop aortic sclerosis in response to an atherogenic diet, and the spontaneous formation of foam cells from peritoneal macrophages is also markedly reduced in these animals. This suggests that the lack of PPAR $\alpha$ protects against the oxidative stress normally seen in THM mice, possibly by reducing Ang II levels [19]. Thus these data, while confirming that PPAR $\alpha$ regulates the RAAS, indicate that $\operatorname{PPAR} \alpha$ activation in this model aggravates hypertension and fails to protect against atherogenesis.

\section{Angiotensin-II Receptor Blockade and Actions of PPAR/RXR Heterodimers}

Angiotensin receptor blockers (ARBs) are used to treat hypertension $[25,46]$. The protective effects of ARBs are based on blockade of AT-R1s. In addition to blocking signaling downstream of AT-R1s, this blockade diverts Ang II to Ang II type 2 receptors (AT-R2s), resulting in release of the vasodilator nitric oxide (NO) [46] (Figure 2). In clinical practice, blockade of AT-R1s is often combined with ACE-inhibition, and this treatment strategy (known as 


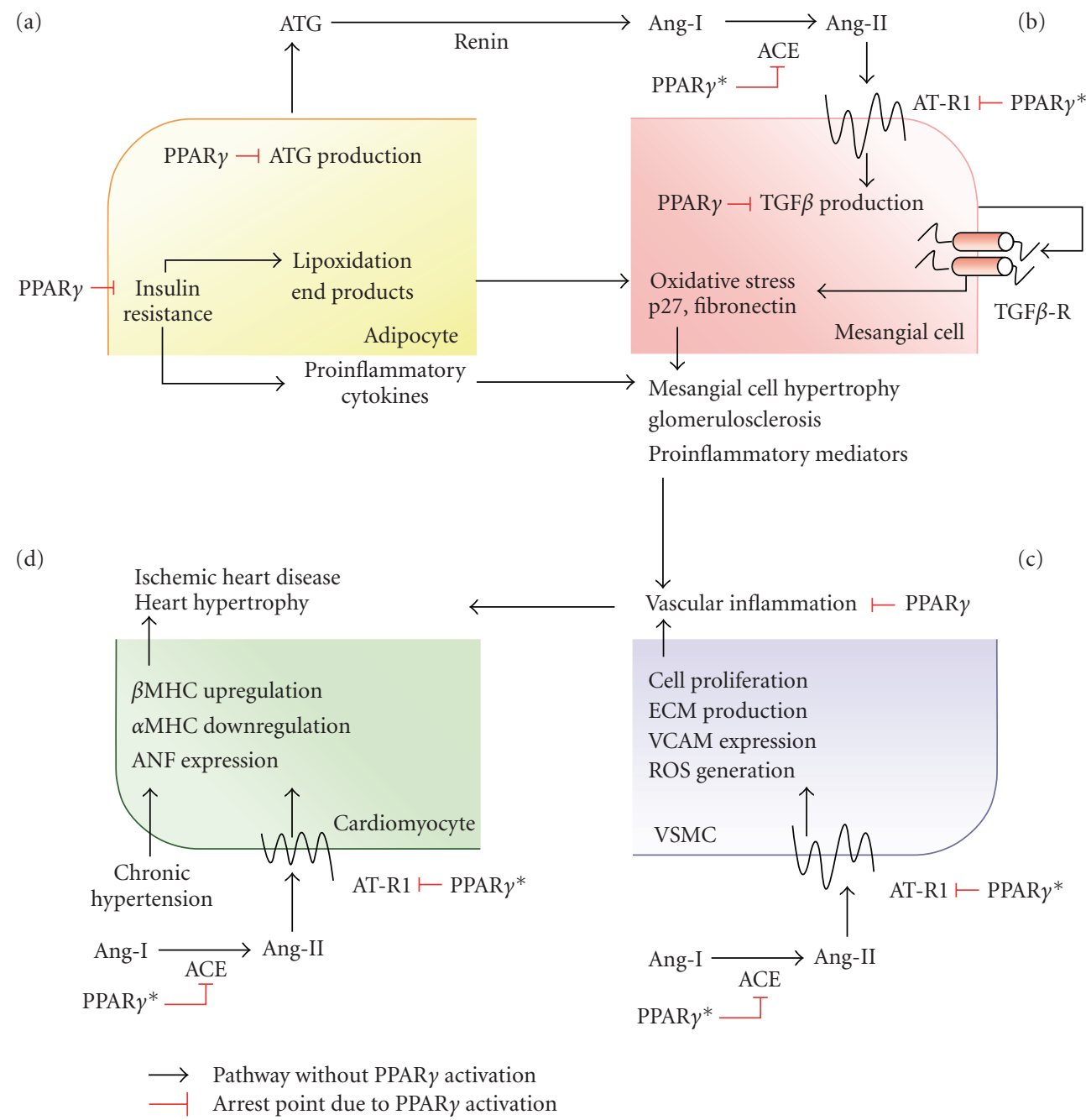

Figure 3: Paracrine effects of the RAAS and their modulation by PPAR $\gamma$. In adipocytes (a) PPAR $\gamma$ activation is suggested to reduce ATG synthesis, impeding RAAS activation; this can ameliorate hypertension in obese diabetic patients. Independently of RAAS modulation, PPAR $\gamma$ improves insulin action in adipocytes, reducing the production of proinflammatory cytokines and reducing the risk of atherogenesis and nephropathy. In kidney mesangial cells (b) PPAR $\gamma$ activation reduces TGF $\beta$-mediated hypertrophy and downregulates expression of AT-R1 and ACE. Some PPAR $\gamma$ ligands, such as telmisartan, combine AT-R1 blocking and ACE inhibitor properties, effectively inhibiting the proinflammatory actions of Ang-II in the kidney. This dual action can also reduce vascular inflammation resulting from VSMC dysfunction (c) and cardiomyocyte hyprtreophy in chronic hypertension (d). We labeled with asterisks PPAR $\gamma$, where its ligands can act through both direct AT-R1 inhibition and downregulation of ACE/AT-R1 gene expression. TGF $\beta$ : transforming growth factor- $\beta$, ECM: extracellular matrix, VCAM: vascular cell adhesion molecule, ROS: reactive oxygen species, $\alpha$ MHC/ $\beta$ MHC: myosin heavy chain $\alpha / \beta$, ANF: atrial natriuretic factor.

double RAAS blockade) can effectively reduce blood pressure in high-risk patients [46]. The advantage of ACE inhibitors is their ability to reduce circulating and tissue Ang II levels, while ARBs potentiate the beneficial blood pressure lowering effects of bradykinin, including AT-R2 mediated generation of NO (Figure 2).

Two ARBs, telmisartan and irbesartan, act as selective PPAR modulators (SPPARMs) [36, 49, 51, 52]. Selective $\operatorname{PPAR} \gamma$ modulation is a new and promising pharmacological approach, based on selective receptor-cofactor interactions and target gene regulation without unwanted PPAR $y$ side effects, such as the well-known water and sodium retention associated with TZD treatment [36, 53]. Due to its partial PPAR $\gamma$ agonist effect, telmisartan inhibits vascular ACE activity [13], AT-R1 expression [54, 55] and increases endothelial NO synthesis [56], preventing oxidative stress and endothelial dysfunction more effectively than non PPAR $\gamma$-agonist ARBs [13]. Longterm treatment (4-24 weeks) with telmisartan, in monotherapy or in combination with other antihypertensive drugs reduces systolic blood pressure by $4-4.6 \mathrm{mmHg}$ and diastolic blood pressure by $3-$ $3.6 \mathrm{mmHg}$ [57]. This compares favorably with the reduction of systolic blood pressure by $3 \mathrm{mmHg}$ by pioglitazone in the Prospective Pioglitazone Clinical Trial in Macrovascular Events (PROactive) study $[21,58]$. This degree of improvement provides sustained blood pressure control of mild to 
moderate hypertension [59]. In particular, the PROactive study indicates a clear clinical benefit of pioglitazone in the risk reduction of cardiovascular events in patients with type 2 diabetes, since addition of pioglitazone to conventional antihypertensive therapy reduced macrovascular outcomes by $10 \%$, nonfatal myocardial infarction and stroke by $16 \%$ compared with placebo [60]. Pioglitazone might combine antidiabetic, antiinflammatory and antiatherogenic benefits with antihypertensive action of PPAR $\gamma$ activation [60]. However, the recent Rosiglitazone Evaluated for Cardiac Outcomes and Regulation of glycaemia in Diabetes (RECORD) trial confirmed the increased risk of heart failure events in people treated with rosiglitazone, which limits the future use of TZDs in hypertensive patients [61]. Telmisartan was expected to provide a new therapeutic option for improved cardiovascular risk management in metabolic diseases since additionally to its ARB activity, it binds to PPARy [55]. However, neither the Ongoing Telmisartan Alone and Combination with Ramipril Global End Point Trial (ONTARGET) nor the Telmisartan Randomized Assesment Study in ACE-1 Intolerant Subjects (TRANSCEND) showed any significant advantage of telmisartan in reducing cardiovascular endpoints in high-risk patients [62].

PPAR $\gamma$ also blocks the action of Ang II by transcriptionally repressing AT-R1 gene expression in VSMCs $[16,36$, $49,51,54$ ] (Figure 2). In addition to its role as a regulator of vascular tone, AT-R1 activation contributes to vascular lesions and atherogenesis by promoting VSMC proliferation [32, 63]; therefore a suppressed Ang II response can potentially slow the progression of atherosclerosis. VSMCs express the retinoid receptors $\operatorname{RAR} \alpha$ and $\operatorname{RXR} \alpha$. In the arterial wall, long-term exposure to all-trans retinoic acid or $\operatorname{RAR} \alpha / \operatorname{RXR} \alpha$ agonists dose-dependently inhibits Ang II-induced VSMC proliferation and the expression of $\mathrm{c}$-fos and transforming growth factor- $\beta$ (TGF $\beta$ ) mRNA, providing antiproliferative/antiinflammatory benefits and vascular protection in hypertensive patients $[16,63]$. The likely mechanism of the reduced Ang II response upon retinoid receptor activation is RAR/RXR mediated downregulation of AT-R1 expression in VSMCs, similar to the action of PPAR $y$ ligands [16]. AngII-mediated vascular damage and endothelial dysfunction in rats are also reduced by the activation of PPAR $\alpha$, but this effect is due to the elevated endothelial NO synthesis and reduced oxidative stress and not to AT-R1 blockade [64].

\section{PPAR $\gamma$ Ligands Reduce Aldosterone Levels: Vasoprotection and Cardioprotection}

The main effect of aldosterone is to facilitate epithelial sodium and water resorbtion, leading to the expansion of total body fluid volume and secondarily contributing to the elevation of systemic blood pressure [25]. Permanently high aldosterone production causes microvascular injury and cardiac hypertrophy, major contributors to hypertensionassociated cardiovascular morbidity and mortality [46].

Ang II is the main trigger of aldosterone secretion in the adrenal cortex, and AT-R1 blockers therefore reduce plasma aldosterone levels [65]. Recent studies indicate that the PPAR $y$ agonist telmisartan, which is an ARB and reduces vascular ACE activity through $\operatorname{PPAR} \gamma$, is more effective at reducing aldosterone levels than non-PPAR $\gamma$ ligand ARBs $[36,51,65]$. PPAR $\gamma$ ligands such as rosiglitazone and PD168 cause a significant drop in blood pressure in hypertensive rats, and increase urinary aldosterone excretion [18]. The reduced heart-to-body weight ratio of ligand-treated animals indicates that PPAR $\gamma$ activation can also diminish aldosterone-induced heart hypertrophy [18]. These results support the idea that AT-R1 blockade in combination with PPAR $y$ stimulation has a more potent aldestrerone-lowering effect than ACE-inhibition alone, and is a promising strategy for preventing the increased body fluid volume and cardiac and vascular damage induced by enhanced RAAS activity (Figure 3).

\section{Volume Overload is the Adverse Effect of PPAR $\gamma$ Activation}

Although PPAR $y$ stimulation reduces aldosterone levels, thereby countering water and sodium reabsorption, PPAR $p$ ligands such as rosiglitazone and PD168, concomitantly with their antihypertensive effects, cause a significant elevation of total body fluid volume in hypertensive rats [18]. Similarly, edema and water retention are frequently occurring side effects in many patients treated with TZDs $[3,34,35,66,67]$. This effect can normally be treated with diuretics; however, this cannot fully restore the interstitial fluid volume in TZD-treated diabetic or atherosclerotic patients if glomerulosclerosis or diabetic glomerulonephritis with osmotic diuresis has developed. Adverse metabolic effects of loop diuretics also contraindicate their administration in many cases $[35,67]$.

Fluid retention caused by TZDs might be a consequence of the activation of PPAR $\gamma$ expressed in the kidney collecting ducts, since kidney epithelial PPAR $y$ positively regulates sodium and water resorbtion [68]. Other factors besides the enhanced sodium resorbtion might also be involved in the edematous side effects of PPAR $y$ ligands, since individuals with single nucleotide polymorphisms in the $\beta 1$ adrenergic receptor gene develop peripheral edema more frequently during PPAR $\gamma$ agonist treatment [69]. In contrast, polymorphisms in the PPAR $\gamma$ regulated renin and endothelin-1 genes are associated with a reduced risk of water retention and edema [69].

Fluid retention upon PPAR $\gamma$ ligand administration does not seem to interfere with the beneficial blood pressure lowering effects of these drugs [18]; however, four large trials of TZDs with cardiovascular endpoints have underlined the harmful side effects of PPAR $y$ activation in diabetic patients with hypertension or accompanying heart problems [34]. Although PPAR $y$ agonists reduce cardiovascular risk factors $[3,21]$, congestive heart failure or other ischemic heart diseases can develop unexpectedly in patients treated with TZDs [34]. Edema and fluid retention provide a possible explanation for this, since expansion of extracellular fluid volume diminishes cardiac output, triggering a compensatory cardiac hypertrophy, eventually resulting in 
congestive heart failure [34]. To avoid unwanted cardiac side effects, administration of TZDs is being restricted, and much attention is being directed to the development of SPPARMs in order to improve the safety of PPAR $\gamma$ modulation [57].

\section{RAAS Dependent Renal Injury Is a Risk Factor for Hypertension: Renoprotective PPAR $\gamma$}

Dysfunction of the RAAS can develop into kidney disease, which can both contribute to and be exacerbated by high blood pressure and cardiovascular morbidity [70, 71] (Figure 3). The importance of RAAS blockade in the treatment of nephropathy has been clearly established, although the renal benefits of ARBs and ACE inhibitors seem to be independent of their blood pressure lowering effects [71]. Several lines of evidence indicate that the local actions of the RAAS are not only involved in the regulation of renal hemodynamics, but also play a central role in kidney inflammation and the progression of microvascular lesions [70-76]. Recent reports indicate that Ang II has proinflammatory, mitogenic and proapoptotic effects; and therefore intrarenal Ang II production is an important factor in the initiation of glomerular and tubulointerstitial inflammation, contributing to the development of nephropathy, vascular injury and hypertension [73-78].

Spontaneously hypertensive rats or rats with streptozotocin-induced diabetes develop significant glomerular damage, characterized by sclerosis, hypercellularity, podocyte injury with abnormal urinary protein excretion, and tubulointerstitial inflammation characterized by fibrosis, type IV collagen staining and expression of TGF $\beta[47,71$, 74]. Other hallmarks of kidney disease are enhanced activity of Ang II, with increased AT-R1 expression and downregulated expression of PPAR $\gamma$ [71]. All these indicators of glomerular and tubulointerstitial damage can be improved by administration of ARBs [48, 71].

Reduction of blood pressure without RAAS blockade is, however, less effective in the mitigation of renal disease. Thus underlines the fact that kidney injury is primarily due to the inflammatory, proliferative and thrombotic effects of Ang II, which adversely affect renal perfusion and increase oxidative stress [33, 71, 75-79]. Clinical evidence suggests that telmisartan, the PPAR $\gamma$ ligand ARB, is more potent than other ARBs or ACE inhibitors at slowing the development of nephropathy $[49,51,76]$. Telmisartan also attenuates renal damage in salt-induced hypertensive rats, possibly due to the improved endothelial NO synthase coupling and renal autoregulation [80]. Other PPAR $\gamma$ ligands, such as TZDs, also decrease inflammatory hallmarks in the kidney, such as glomerular cell proliferation, apoptosis, and podocyte injury; moreover, these ligands can also reduce the inflammatory response to Ang II in kidney mesangial cells $[13,23,48$, 75]. The Diabetes REduction Assesment with ramipril and rosiglitazone Medication (DREAM) trial reported that RAAS blockade with the ACE inhibitor ramipril can not alter renal outcome in patients with impaired glucose tolerance and/or impaired fasting glucose levels [81], while the same study confirmed that the TZD-type PPAR $y$ ligand rosiglitazone reduces diabetic kidney complications. The mechanism of renoprotection by PPAR $y$ agonists is multifactorial, and besides antiinflammatory actions includes antifibrotic effects and suppression of the RAAS [23]. Rosiglitazone appears to reduce AT-R1 expression in the kidney, in addition to its repression of Ang II synthesis, while the ARB action of telmisartan makes this compound a promising agent that combines the classical antiinflammatory PPAR $y$ functions with a potent blood pressure lowering effect $[47,70-78,82]$. Due to its lipophilic character and long half-life, telmisartan is considered to have therapeutic potential not only in RAASdependent hypertension, but also in the treatment of diabetic kidney injury [70, 77, 79]. In contrast with $\operatorname{PPAR} \gamma$, the possible role of PPAR $\alpha$ in the modulation of local RAAS activation in the kidney remains undefined. A recent study documented that increased PPAR $\alpha$ expression can also play a protective role in hypertensive renal injury in rats with hypertension induced by $\mathrm{NO}$ withdrawal and high salt diet [83]. However, although plasma RAAS activity is reduced in rats with high-salt diet induced hypertension, local RAAS activation in the kidney leads to severe renal damage [77-80].

\section{Involvement of PPAR $\gamma$ in the Effects of RAAS Blockade on Lipid and Carbohydrate Metabolism}

Inhibition of the RAAS delays or prevents the development of diabetes [52, 84]. The mechanisms underlying this protective effect appear to be complex and might involve the adipose tissue RAAS, which plays an important role in the metabolism of this tissue, including regulation of the production of pro-inflammatory and antiinflammatory adipocytokines [82, 85, 86] (Figure 3).

The regulation of PPAR $y$ expression by aldosterone and Ang-II might influence insulin sensitivity [57, 85]. In rats, chronic treatment with AT-R1 antagonist leads to hypotrophy of epididymal and retroperitoneal adipose tissue, and this is followed by reduced serum levels of leptin and increased levels of adiponectin [87]. Furthermore, ATR1 blockade increases epididymal expression of AT-R2, fatty acid synthase and PPAR $\gamma$, and decreases the expression of tumor necrosis factor alpha $(\mathrm{TNF} \alpha)$. Adipokine synthesis and reduced $\mathrm{TNF} \alpha$ production within adipose tissue are therefore beneficial consequences of local AT-R1 inhibition, AT-R2 stimulation, and perhaps PPAR $y$ activation [87]. A recent study assessed the binding affinity of the ARBs telmisartan, valsartan and lisinopril to PPAR $\gamma$, finding that telmisartan is the most potent PPAR $\gamma$ agonist [88]. In the same study, all tested ARBs increased the phosphorylation of insulin-like growth factor receptor-1 and AKT in skeletal muscle cells, and also increased the secretion of the adipokine visfatin by adipocytes [88]. In hypertensive diabetic rats telmisartan improves the metabolic profile and reduces blood pressure to normotensive values faster than the ARB valsartan or the TZD pioglitazone [89]. In addition, telmisartan increases macrophage cholesterol efflux by enhancing expression of the ATP binding cassette 
transporters A1 and G1 (ABCA1/G1) and of scavenger receptor class B type I, and these effects are dependent on PPAR $\gamma$ regulated pathways [90]. The obesity-associated decrease in adiponectin and the increase in proinflammatory adipokines are linked to the development of insulin resistance, which is coupled to altered macrophage lipid metabolism, enhanced atherogenesis; and hypertension [1,2]. The consequences of PPAR $\gamma$ activation on insulin signaling, adiponectin and adipokine gene expression, as well as macrophage cholesterol handling, might underlie the mechanism of the additional antidiabetic and vasoporotective effects of AT-R1 blockade.

The metabolic benefits of RAAS blockade have been challenged by the DREAM trial. This study shows that the ACE inhibitor ramipril does not reduce new-onset diabetes, although it does significantly increase the regression to normogylcemia, suggesting beneficial effects on glucose homeostasis [91]. The DREAM trial involved a relatively young patient population with moderate hypertension and without cardiovascular disease, which might explain the lack of an effect on new-onset diabetes [81, 91]. The question of whether the prevention of new-onset diabetes leads to a reduction in cardiovascular disease events might be resolved by the results of two ongoing clinical trials, Nateglinide And Valsartan in Impaired Glucose Tolerance Outcomes Research (NAVIGATOR) and ACE Inhibitor-based versus Diuretic-based Antihypertensive Primary Treatment in Patients with PreDiabetes (ADaPT) [62].

\section{Conclusion and Outlook}

Gene expression of RAAS molecules is modulated by PPAR $\gamma$, and to a lesser extent by $\operatorname{PPAR} \alpha$, making the ligands of these transcription factors potential blood pressure modulating drugs in RAAS-dependent hypertension [3, 21, 70]. The blood pressure reduction achieved by PPAR $\gamma$ ligands suggests that PPAR $\gamma$ activation can be used in the long-term control of moderate hypertension [92]. Nephropathy, a predisposing risk factor for hypertension, can be also ameliorated by $\operatorname{PPAR} \gamma$ and PPAR $\alpha$, athough these renoprotective effects are due to antiinflammatory and vasoprotective PPAR $\gamma / \operatorname{PPAR} \alpha$ properties and the reduction in the proinflammatory Ang II effects, and are independent of the systemic RAAS modulation. Transcription of angiotensinogen seems also to be regulated by $\operatorname{PPAR} \alpha$, although the value of PPAR $\alpha$ as a therapeutic target in RAAS dependent hypertension should be evaluated.

Since activation of PPAR $\gamma$ modulates both the systemic and paracrine effects of the RAAS, selective PPAR $\gamma$ modulators may provide blood pressure lowering benefits with synergistic vasoprotective, renoprotective and cardioprotective consequences. However, TZD-type PPAR $\gamma$ ligands disturb water and salt homeostasis in susceptible individuals, leading to adverse cardiac side effects, which is today a strong limitation for the use and future impact of the currently available PPAR $\gamma$ activators. The development of SPPARMs and further studies in mice with tissue specific deletion of PPAR isoforms will facilitate better understanding and pharmacological modulation of nuclear receptor functions in hypertension.

\section{Abbreviations}

ACE: Angiotensin I converting enzyme

Ang I: Angiotensin I

Ang II: Angiotensin II

AT-R1: Angiotensin II receptor type 1

ADH: Antidiuretic hormone

ANF: Atrial natriuretic factor

AT-R2: Angiotensin II receptor type 2

ATG: Angiotensinogen

ARB: $\quad$ Angiotensin II type 1 receptor blocker

JGA: Juxtaglomerular apparatus

RAAS: Renin-angiotensin-aldosterone system

SPPARM: Selective PPAR modulator

VSMC: Vascular smooth muscle cell.

\section{Acknowledgments}

T. Rőszer was supported by the "People" Marie Curie IntraEuropean Fellowships Programme and M. Ricote by the Spanish Ministry of Science and Innovation (SAF200907466), the Fundación "Mutua Madrileña", the Fundació La Marató de TV3, and the Ramón y Cajal Programme. The CNIC is supported by the Spanish Ministry of Science and Innovation and the Pro-CNIC Foundation. The authors thank Dr. Christian Hellriegel (CNIC, Madrid) and Dr. Ivan J. Núñez Gil (Cardiovascular Institute, Hospital Clínico San Carlos, Madrid) for critical reading of the manuscript and Simon Bartlett (CNIC) for editorial assistance.

\section{References}

[1] S. Heikkinen, J. Auwerx, and C. A. Argmann, "PPARy in human and mouse physiology," Biochimica et Biophysica Acta, vol. 1771, no. 8, pp. 999-1013, 2007.

[2] G. Medina-Gómez, S. Gray, and A. Vidal-Pluig, "Role of PPARs in the pathogenesis of the metabolic syndrome," in The Metabolic Syndrome at the Beginning of the 21st Century, M. Serrano, J. F. Caro, R. Carraro, and J. A. Gutiérez Fuentes, Eds., pp. 264-265, Elsevier, Madrid, Spain, 2005.

[3] S. Z. Duan, C. Y. Ivashchenko, M. G. Usher, and R. M. Mortensen, "PPAR- $\gamma$ in the cardiovascular system," PPAR Research, vol. 2008, Article ID 745804, 10 pages, 2008.

[4] Y. Takata, J. Liu, F. Yin, et al., "PPAR $\delta$-mediated antiinflammatory mechanisms inhibit angiotensin II-accelerated atherosclerosis," Proceedings of the National Academy of Sciences of the United States of America, vol. 105, no. 11, pp. 42774282, 2008.

[5] A. Meirhaeghe and P. Amouyel, "Impact of genetic variation of PPAR $\gamma$ in humans," Molecular Genetics and Metabolism, vol. 83, no. 1-2, pp. 93-102, 2004.

[6] M. Horiki, H. Ikegami, T. Fujisawa, et al., "Association of Pro12Ala polymorphism of PPAR $\gamma$ gene with insulin resistance and related diseases," Diabetes Research and Clinical Practice, vol. 66, pp. S63-S67, 2004.

[7] N. Wang, J. D. Symons, H. Zhang, Z. Jia, F. J. Gonzalez, and T. Yang, "Distinct functions of vascular endothelial and smooth 
muscle PPAR $\gamma$ in regulation of blood pressure and vascular tone," Toxicologic Pathology, vol. 37, no. 1, pp. 21-27, 2009.

[8] P. Obih and A. Oyekan, "Regulation of blood pressure, natriuresis and renal thiazide/amiloride sensitivity in PPAR $\alpha$ null mice," Blood Pressure, vol. 17, no. 1, pp. 55-63, 2008.

[9] R. Komers and A. Vrána, "Thiazolidinediones—-tools for the research of metabolic syndrome X," Physiological Research, vol. 47, no. 4, pp. 215-225, 1998.

[10] C. Yagil and Y. Yagil, "Peroxisome proliferator-activated receptor- $\alpha$ : friend or foe?” Hypertension, vol. 50, no. 5, pp. 847-850, 2007.

[11] J. J. Nolan, B. Ludvik, P. Beerdsen, M. Joyce, and J. Olefsky, "Improvement in glucose tolerance and insulin resistance in obese subjects treated with troglitazone," The New England Journal of Medicine, vol. 331, no. 18, pp. 1188-1193, 1994.

[12] M. St John Sutton, M. Rendell, P. Dandona, et al., "A comparison of the effects of rosiglitazone and glyburide on cardiovascular function and glycemic control in patients with type 2 diabetes," Diabetes Care, vol. 25, no. 11, pp. 2058-2064, 2002.

[13] S. Takai, D. Jin, M. Kimura, et al., "Inhibition of vascular angiotensin-coverting enzyme by telmisartan via the peroxisome proliferator-activated receptor $\gamma$ agonistic property in rats," Hypertension Research, vol. 30, no. 12, pp. 1231-1237, 2007.

[14] H. Toba, S. Miki, T. Shimizu, et al., "The direct antioxidative and anti-inflammatory effects of peroxisome proliferatoractivated receptors ligands are associated with the inhibition of angiotensin converting enzyme expression in streptozotocininduced diabetic rat aorta," European Journal of Pharmacology, vol. 549, no. 1-3, pp. 124-132, 2006.

[15] M. J. Ryan, S. P. Didion, S. Mathur, F. M. Faraci, and C. D. Sigmund, "PPAR $\gamma$ agonist rosiglitazone improves vascular function and lowers blood pressure in hypertensive transgenic mice," Hypertension, vol. 43, no. 3, pp. 661-666, 2004.

[16] K. Takeda, T. Ichiki, Y. Funakoshi, K. Ito, and A. Takeshita, "Downregulation of angiotensin II type 1 receptor by all-trans retinoic acid in vascular smooth muscle cells," Hypertension, vol. 35, no. 1, pp. 297-302, 2000.

[17] V. Haxsen, S. Adam-Stitah, E. Ritz, and J. Wagner, "Retinoids inhibit the actions of angiotensin II on vascular smooth muscle cells," Circulation Research, vol. 88, no. 6, pp. 637-644, 2001.

[18] E. R. Blasi, J. Heyen, M. Hemkens, A. McHarg, C. M. Ecelbarger, and S. Tiwari, "Effects of chronic PPAR-agonist treatment on cardiac structure and function, blood pressure, and kidney in healthy sprague-dawley rats," PPAR Research, vol. 2009, Article ID 237865, 13 pages, 2009.

[19] K. M. Tordjman, C. F. Semenkovich, T. Coleman, et al., "Absence of peroxisome proliferator-activated receptor- $\alpha$ abolishes hypertension and attenuates atherosclerosis in the Tsukuba hypertensive mouse," Hypertension, vol. 50, no. 5, pp. 945-951, 2007.

[20] M. Hamblin, L. Chang, J. Zhang, and Y. E. Chen, "The role of peroxisome proliferator-activated receptor $\gamma$ in blood pressure regulation," Current Hypertension Reports, vol. 11, no. 4, pp. 239-245, 2009.

[21] T. D. Giles and G. E. Sander, "Effects of thiazolidinediones on blood pressure," Current Hypertension Reports, vol. 9, no. 4, pp. 332-337, 2007.

[22] I. J. Jonkers, F. H. de Man, A. van der Laarse, et al., "Bezafibrate reduces heart rate and blood pressure in patients with hypertriglyceridemia," Journal of Hypertension, vol. 19, no. 4, pp. 749-755, 2001.
[23] M. C. Lansang, C. Coletti, S. Ahmed, M. S. Gordon, and N. K. Hollenberg, "Effects of the PPAR- $\gamma$ agonist rosiglitazone on renal haemodynamics and the renin-angiotensin system in diabetes," Journal of the Renin-Angiotensin-Aldosterone System, vol. 7, no. 3, pp. 175-180, 2006.

[24] Y. Shimamoto, K. Hirota, and A. Fukamizu, "Effect of peroxisome proliferator-activated receptor $\alpha$ on human angiotensinogen promoter," International Journal of Molecular Medicine, vol. 13, no. 5, pp. 729-733, 2004.

[25] H. Kobori, M. Nangaku, L. G. Navar, and A. Nishiyama, "The intrarenal renin-angiotensin systemml: from physiology to the pathobiology of hypertension and kidney disease," Pharmacological Reviews, vol. 59, no. 3, pp. 251-287, 2007.

[26] L. Yvan-Charvet, F. Massiéra, N. Lamandé, et al., "Deficiency of angiotensin type 2 receptor rescues obesity but not hypertension induced by overexpression of angiotensinogen in adipose tissue," Endocrinology, vol. 150, no. 3, pp. 14211428, 2009.

[27] H. Lu, C. M. Boustany-Kari, A. Daugherty, and L. A. Cassis, "Angiotensin II increases adipose angiotensinogen expression," American Journal of Physiology, vol. 292, no. 5, pp. E1280-E1287, 2007.

[28] H. Lu, D. L. Rateri, D. L. Feldman, et al., "Renin inhibition reduces hypercholesterolemia-induced atherosclerosis in mice," Journal of Clinical Investigation, vol. 118, no. 3, pp. 984993, 2008.

[29] M. Gupte, C. M. Boustany-Kari, K. Bharadwaj, et al., "ACE2 is expressed in mouse adipocytes and regulated by a high-fat diet," American Journal of Physiology, vol. 295, no. 3, pp. R781R788, 2008.

[30] B. Gálvez-Prieto, J. Bolbrinker, P. Stucchi, et al., "Comparative expression analysis of the renin-angiotensin system components between white and brown perivascular adipose tissue," Journal of Endocrinology, vol. 197, no. 1, pp. 55-64, 2008.

[31] F. Sugiyama, S. Haraoka, T. Watanabe, et al., "Acceleration of atherosclerotic lesions in transgenic mice with hypertension by the activated renin-angiotensin system," Laboratory Investigation, vol. 76, no. 6, pp. 835-842, 1997.

[32] N. Nishijo, F. Sugiyama, K. Kimoto, et al., "Salt-sensitive aortic aneurysm and rupture in hypertensive transgenic mice that overproduce angiotensin II," Laboratory Investigation, vol. 78, no. 9, pp. 1059-1066, 1998.

[33] P. Bichu, R. Nistala, A. Khan, J. R. Sowers, and A. WhaleyConnell, "Angiotensin receptor blockers for the reduction of proteinuria in diabetic patients with overt nephropathy: results from the AMADEO study," Vascular Health and Risk Management, vol. 5, pp. 129-140, 2009.

[34] J. G. Robinson, "Should we use PPAR agonists to reduce cardiovascular risk?” PPAR Research, vol. 2008, Article ID 891425, 13 pages, 2008.

[35] S. Sena, I. R. Rasmussen, A. R. Wende, et al., "Cardiac hypertrophy caused by peroxisome proliferator-activated receptor$\gamma$ agonist treatment occurs independently of changes in myocardial insulin signaling," Endocrinology, vol. 148, no. 12, pp. 6047-6053, 2007.

[36] M. Schupp, M. Clemenz, R. Gineste, et al., "Molecular characterization of new selective peroxisome proliferatoractivated receptor $\gamma$ modulators with angiotensin receptor blocking activity," Diabetes, vol. 54, no. 12, pp. 3442-3452, 2005.

[37] V. T. Todorov, M. Desch, N. Schmitt-Nilson, A. Todorova, and A. Kurtz, "Peroxisome proliferator-activated receptor$\gamma$ is involved in the control of renin gene expression," Hypertension, vol. 50, no. 5, pp. 939-944, 2007. 
[38] R. Di Nicolantonio, L. Lan, and A. Wilks, "Nucleotide variations in intron 1 of the renin gene of the spontaneously hypertensive rat," Clinical and Experimental Hypertension, vol. 20, no. 1, pp. 27-40, 1998.

[39] V. T. Todorov, M. Desch, T. Schubert, and A. Kurtz, "The $\mathrm{Pal} 3$ promoter sequence is critical for the regulation of human renin gene transcription by peroxisome proliferator-activated receptor- $\gamma$," Endocrinology, vol. 149, no. 9, pp. 4647-4657, 2008.

[40] M. Desch, A. Schreiber, F. Schweda, et al., "Increased renin production in mice with deletion of peroxisome proliferatoractivated receptor- $\gamma$ in juxtaglomerular cells," Hypertension, vol. 55, no. 3, pp. 660-666, 2010.

[41] D. Takahashi, K. Tamura, T. Ushikubo, et al., "Relationship between hepatic angiotensinogen mRNA expression and plasma angiotensinogen in patients with chronic hepatitis," Life Sciences, vol. 60, no. 18, pp. 1623-1633, 1997.

[42] L. J. Bloem, A. K. Manatunga, D. A. Tewksbury, and J. H. Pratt, "The serum angiotensinogen concentration and variants of the angiotensinogen gene in white and black children," Journal of Clinical Investigation, vol. 95, no. 3, pp. 948-953, 1995.

[43] N. Tomita, R. Morishita, J. Higaki, et al., "Effect of angiotensinogen on blood pressure regulation in normotensive rats: application of a loss of function approach," Journal of Hypertension, vol. 13, no. 12, pp. 1767-1774, 1995.

[44] Y.-S. Tsai, H.-J. Kim, N. Takahashi, et al., "Hypertension and abnormal fat distribution but not insulin resistance in mice with P465L PPAR $\gamma$," Journal of Clinical Investigation, vol. 114, no. 2, pp. 240-249, 2004.

[45] J. Rieusset, J. Auwerx, and H. Vidal, "Regulation of gene expression by activation of the peroxisome proliferatoractivated receptor $\gamma$ with rosiglitazone (BRL 49653) in human adipocytes," Biochemical and Biophysical Research Communications, vol. 265, no. 1, pp. 265-271, 1999.

[46] T. Unger and M. Stoppelhaar, "Rationale for double reninangiotensin-aldosterone system blockade," American Journal of Cardiology, vol. 100, no. 3, pp. S25-S31, 2007.

[47] J. Song, H. Liu, H. W. Ressom, S. Tiwari, and C. M. Ecelbarger, "Chronic rosiglitazone therapy normalizes expression of ACE1, SCD1 and other genes in the kidney of obese zucker rats as determined by microarray analysis," Experimental and Clinical Endocrinology and Diabetes, vol. 116, no. 6, pp. 315325, 2008.

[48] S. Efrati, S. Berman, E. Ilgiyeav, Z. Averbukh, and J. Weissgarten, "PPAR- $\gamma$ activation inhibits angiotensin II synthesis, apoptosis, and proliferation of mesangial cells from spontaneously hypertensive rats," Nephron Experimental Nephrology, vol. 106, no. 4, pp. e107-e112, 2007.

[49] R. A. Sanchez, L. D. Masnatta, C. Pesiney, P. Fischer, and A. J. Ramirez, "Telmisartan improves insulin resistance in high renin nonmodulating salt-sensitive hypertensives," Journal of Hypertension, vol. 26, no. 12, pp. 2393-2398, 2008.

[50] S. Subramanian, M. A. DeRosa, C. Bernal-Mizrachi, et al., "PPAR $\alpha$ activation elevates blood pressure and does not correct glucocorticoid-induced insulin resistance in humans," American Journal of Physiology, vol. 291, no. 6, pp. E1365E1371, 2006.

[51] T. Tagami, H. Yamamoto, K. Moriyama, et al., "A selective peroxisome proliferator-activated receptor $\gamma$ modulator, telmisartan, binds to the receptor in a different fashion from thiazolidinediones," Endocrinology, vol. 150, no. 2, pp. 862870, 2009.

[52] M. Mazerska and M. Myśliwiec, "Telmisartan lowers albuminuria in type 2 diabetic patients treated with angiotensin enzyme inhibitors," Advances in Medical Sciences, vol. 54, no. 1, pp. 37-40, 2009.

[53] X. Liu, L. Lü, B.-B. Tao, and Y.-C. Zhu, "All-trans retinoic acid inhibits the increases in fibronectin and PAI-1 induced by TGF- $\beta 1$ and Ang II in rat mesangial cells," Acta Pharmacologica Sinica, vol. 29, no. 9, pp. 1035-1041, 2008.

[54] I. Imayama, T. Ichiki, K. Inanaga, et al., "Telmisartan downregulates angiotensin II type 1 receptor through activation of peroxisome proliferator-activated receptor $\gamma$," Cardiovascular Research, vol. 72, no. 1, pp. 184-190, 2006.

[55] P. Gosse, "A review of telmisartan in the treatment of hypertension: blood pressure control in the early morning hours," Vascular Health and Risk Management, vol. 2, no. 3, pp. 195-201, 2006.

[56] N. Kobayashi, T. Ohno, K. Yoshida, et al., "Cardioprotective mechanism of telmisartan via PPAR- $\gamma$-eNOS pathway in dahl salt-sensitive hypertensive rats," American Journal of Hypertension, vol. 21, no. 5, pp. 576-581, 2008.

[57] S. Yamagishi and M. Takeuchi, "Telmisartan is a promising cardiometabolic sartan due to its unique PPAR- $\gamma$-inducing property," Medical Hypotheses, vol. 64, no. 3, pp. 476-478, 2005.

[58] J. A. Dormandy, B. Charbonnel, D. J. Eckland, et al., "Secondary prevention of macrovascular events in patients with type 2 diabetes in the PROactive Study (PROspective pioglitAzone Clinical Trial in macroVascular Events): a randomised controlled trial," The Lancet, vol. 366, no. 9493, pp. 1279-1289, 2005.

[59] T. Unger and M. Schupp, “Telmisartan: from lowering blood pressure to end-organ protection," Future Cardiology, vol. 1, pp. 7-15, 2005.

[60] R. Rizza, R. Henry, and R. Kahn, "Commentary on the results and clinical implications of the PROactive study," Diabetes Care, vol. 28, no. 12, pp. 2965-2967, 2005.

[61] M. Komajda, J. J. V. McMurray, H. Beck-Nielsen, et al., "Heart failure events with rosiglitazone in type 2 diabetes: data from the RECORD clinical trial," European Heart Journal, vol. 31, no. 7, pp. 824-831, 2010.

[62] J. N. Basile, "Antihypertensive therapy, new-onset diabetes, and cardiovascular disease," International Journal of Clinical Practice, vol. 63, no. 4, pp. 656-666, 2009.

[63] S. Wakino, U. Kintscher, S. Kim, et al., "Retinoids inhibit proliferation of human coronary smooth muscle cells by modulating cell cycle regulators," Arteriosclerosis, Thrombosis, and Vascular Biology, vol. 21, no. 5, pp. 746-751, 2001.

[64] Q. N. Diep, F. Amiri, R. M. Touyz, et al., "PPAR $\alpha$ activator effects on Ang II-induced vascular oxidative stress and inflammation," Hypertension, vol. 40, no. 6, pp. 866-871, 2002.

[65] T. Nakamura, K. Kawachi, Y. Saito, et al., "Effects of ARB or ACE-inhibitor administration on plasma levels of aldosterone and adiponectin in hypertension," International Heart Journal, vol. 50, no. 4, pp. 501-512, 2009.

[66] J. D. Tugwood and C. T. Montague, "Biology and toxicology of PPAR $y$ ligands," Human and Experimental Toxicology, vol. 21, no. 8, pp. 429-437, 2002.

[67] R. W. Nesto, D. Bell, R. O. Bonow, et al., "Thiazolidinedione use, fluid retention, and congestive heart failure: a consensus statement from the American Heart Association and American Diabetes Association," Circulation, vol. 108, no. 23, pp. 2941-2948, 2003.

[68] H. Zhang, A. Zhang, D. E. Kohan, R. D. Nelson, F. J. Gonzalez, and T. Yang, "Collecting duct-specific deletion of peroxisome proliferator-activated receptor $\gamma$ blocks thiazolidinedioneinduced fluid retention," Proceedings of the National Academy 
of Sciences of the United States of America, vol. 102, no. 26, pp. 9406-9411, 2005.

[69] W. J. Geese, W. Achanzar, C. Rubin, et al., "Genetic and gene expression studies implicate renin and endothelin-1 in edema caused by peroxisome proliferator-activated receptor $\gamma$ agonists," Pharmacogenetics and Genomics, vol. 18, no. 10, pp. 903-910, 2008.

[70] P. A. Sarafidis and G. L. Bakris, "Protection of the kidney by thiazolidinediones: an assessment from bench to bedside," Kidney International, vol. 70, no. 7, pp. 1223-1233, 2006.

[71] B. H. Chung, S. W. Lim, K. O. Ahn, et al., "Protective effect of peroxisome proliferator activated receptor $\gamma$ agonists on diabetic and non-diabetic renal diseases," Nephrology, vol. 10, supplement 2, pp. S40-S43, 2005.

[72] E. Ritz, "Renal dysfunction as a novel risk factor: microalbuminuria and cardiovascular risk," Kidney International, Supplement, vol. 67, no. 93, pp. S25-S28, 2005.

[73] J. Weissgarten, S. Berman, S. Efrati, M. Rapoport, Z. Averbukh, and L. Feldman, "Apoptosis and proliferation of cultured mesangial cells isolated from kidneys of rosiglitazonetreated pregnant diabetic rats," Nephrology Dialysis Transplantation, vol. 21, no. 5, pp. 1198-1204, 2006.

[74] A. Benigni, C. Zoja, S. Tomasoni, et al., "Transcriptional regulation of nephrin gene by peroxisome proliferatoractivated receptor- $\gamma$ agonist: molecular mechanism of the antiproteinuric effect of pioglitazone," Journal of the American Society of Nephrology, vol. 17, no. 6, pp. 1624-1632, 2006.

[75] Z. Yousefipour, H. Hercule, L. Truong, A. Oyekan, and M. A. Newaz, "Ciglitazone, a peroxisome proliferator-activated receptor $\gamma$ inducer, ameliorates renal preglomerular production and activity of angiotensin II and thromboxane $\mathrm{A}_{2}$ in glycerol-induced acute renal failure," Journal of Pharmacology and Experimental Therapeutics, vol. 322, no. 2, pp. 461-468, 2007.

[76] T. Matsui, S. Yamagishi, S. Ueda, et al., "Telmisartan, an angiotensin II type 1 receptor blocker, inhibits advanced glycation end-product (AGE)-induced monocyte chemoattractant protein-1 expression in mesangial cells through downregulation of receptor for AGEs via peroxisome proliferatoractivated receptor- $\gamma$ activation," Journal of International Medical Research, vol. 35, no. 4, pp. 482-489, 2007.

[77] D. Watanabe, A. Tanabe, M. Naruse, S. Morikawa, T. Ezaki, and K. Takano, "Renoprotective effects of an angiotensin II receptor blocker in experimental model rats with hypertension and metabolic disorders," Hypertension Research, vol. 32, no. 9, pp. 807-815, 2009.

[78] W. Arozal, K. Watanabe, P. T. Veeraveedu, et al., "Effects of angiotensin receptor blocker on oxidative stress and cardio-renal function in streptozotocin-induced diabetic rats," Biological and Pharmaceutical Bulletin, vol. 32, no. 8, pp. 14111416, 2009.

[79] R. Kalaitzidis and G. L. Bakris, "Effects of angiotensin II receptor blockers on diabetic nephropathy," Journal of Hypertension, vol. 27, supplement 5, pp. S15-S21, 2009.

[80] M. Satoh, Y. Haruna, S. Fujimoto, T. Sasaki, and N. Kashihara, "Telmisartan improves endothelial dysfunction and renal autoregulation in Dahl salt-sensitive rats," Hypertension Research, vol. 33, no. 2, pp. 135-142, 2010.

[81] G. R. Dagenais, H. C. Gerstein, R. Holman, et al., "Effects of ramipril and rosiglitazone on cardiovascular and renal outcomes in people with impaired glucose tolerance or impaired fasting glucose: results of the Diabetes REduction Assessment with ramipril and rosiglitazone Medication (DREAM) trial," Diabetes Care, vol. 31, pp. 1007-1014, 2008.
[82] E. Blessing, M. Preusch, R. Kranzhöfer, et al., "Antiatherosclerotic properties of telmisartan in advanced atherosclerotic lesions in apolipoprotein E deficient mice," Atherosclerosis, vol. 199, no. 2, pp. 295-303, 2008.

[83] M. Newaz, K. Ranganna, L. D. Truong, and A. Oyekan, "Effect of peroxisome proliferator-activated receptor- $\alpha$ siRNA on hypertension and renal injury in the rat following nitric oxide withdrawal and high salt diet," Journal of Hypertension, vol. 27, no. 11, pp. 2223-2231, 2009.

[84] M. F. B. Braga and L. A. Leiter, "Role of renin-angiotensin system blockade in patients with diabetes mellitus," American Journal of Cardiology, vol. 104, no. 6, pp. 835-839, 2009.

[85] A. J. Scheen, "Renin-angiotensin system inhibition prevents type 2 diabetes mellitus - part 2: overview of physiological and biochemical mechanisms," Diabetes and Metabolism, vol. 30, no. 6, pp. 498-505, 2004.

[86] C. Guo, V. Ricchiuti, B. Q. Lian, et al., "Mineralocorticoid receptor blockade reverses obesity-related changes in expression of adiponectin, peroxisome proliferator-activated receptor- $\gamma$, and proinflammatory adipokines," Circulation, vol. 117, no. 17, pp. 2253-2261, 2008.

[87] S. Zorad, J.-T. Dou, J. Benicky, et al., "Long-term angiotensin II AT receptor inhibition produces adipose tissue hypotrophy accompanied by increased expression of adiponectin and PPAR $y$," European Journal of Pharmacology, vol. 552, no. 1-3, pp. 112-122, 2006.

[88] A. Storka, E. Vojtassakova, M. Mueller, et al., "Angiotensin inhibition stimulates PPAR $\gamma$ and the release of visfatin," European Journal of Clinical Investigation, vol. 38, no. 11, pp. 820-826, 2008.

[89] F. Younis, N. Stern, R. Limor, Y. Oron, S. Zangen, and T. Rosenthal, "Telmisartan ameliorates hyperglycemia and metabolic profile in nonobese Cohen-Rosenthal diabetic hypertensive rats via peroxisome proliferator activator receptor- $\gamma$ activation," Metabolism. In press.

[90] K. Nakaya, M. Ayaori, T. Hisada, et al., "Telmisartan enhances cholesterol efflux from THP-1 macrophages by activating PPAR $y$," Journal of Atherosclerosis and Thrombosis, vol. 14, no. 3, pp. 133-141, 2007.

[91] J. Bosch, S. Yusuf, H. C. Gerstein, et al., "Effect of ramipril on the incidence of diabetes," The New England Journal of Medicine, vol. 355, no. 15, pp. 1551-1562, 2006.

[92] G. Derosa, E. Fogari, A. F. G. Cicero, et al., "Blood pressure control and inflammatory markers in type 2 diabetic patients treated with pioglitazone or rosiglitazone and metformin," Hypertension Research, vol. 30, no. 5, pp. 387-394, 2007. 


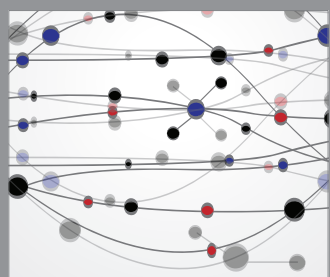

The Scientific World Journal
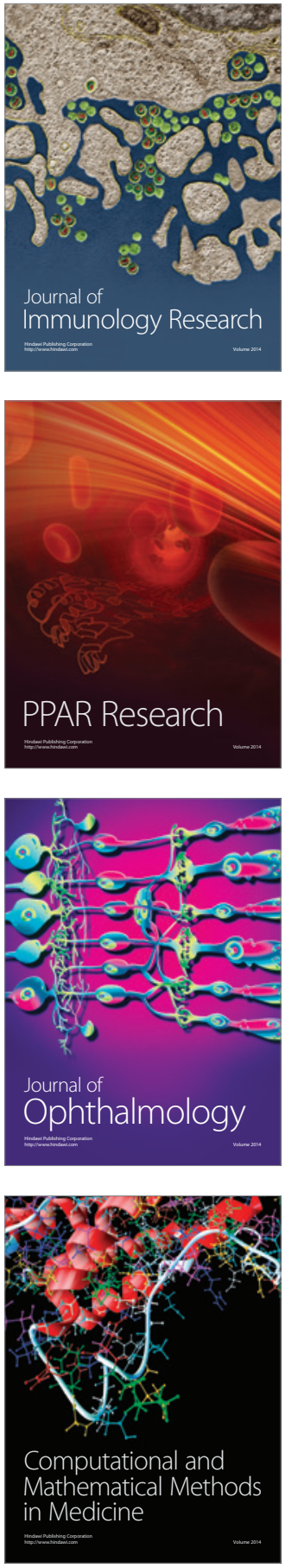

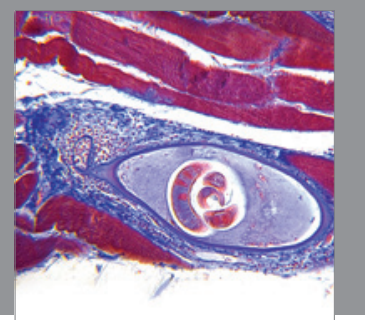

Gastroenterology

Research and Practice
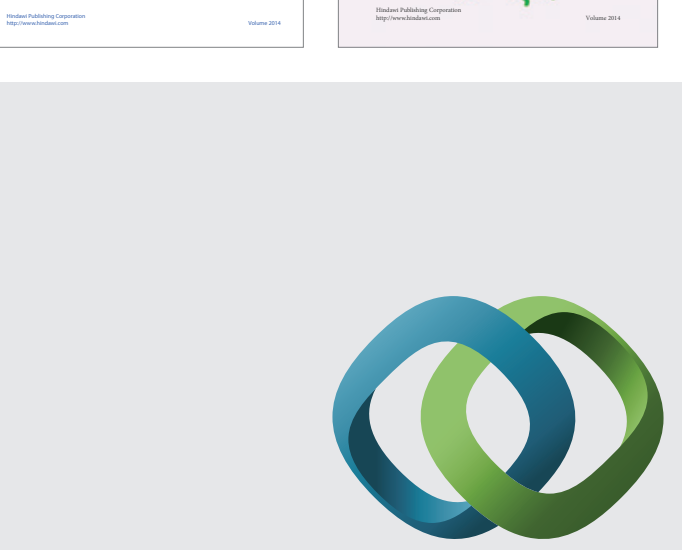

\section{Hindawi}

Submit your manuscripts at

http://www.hindawi.com
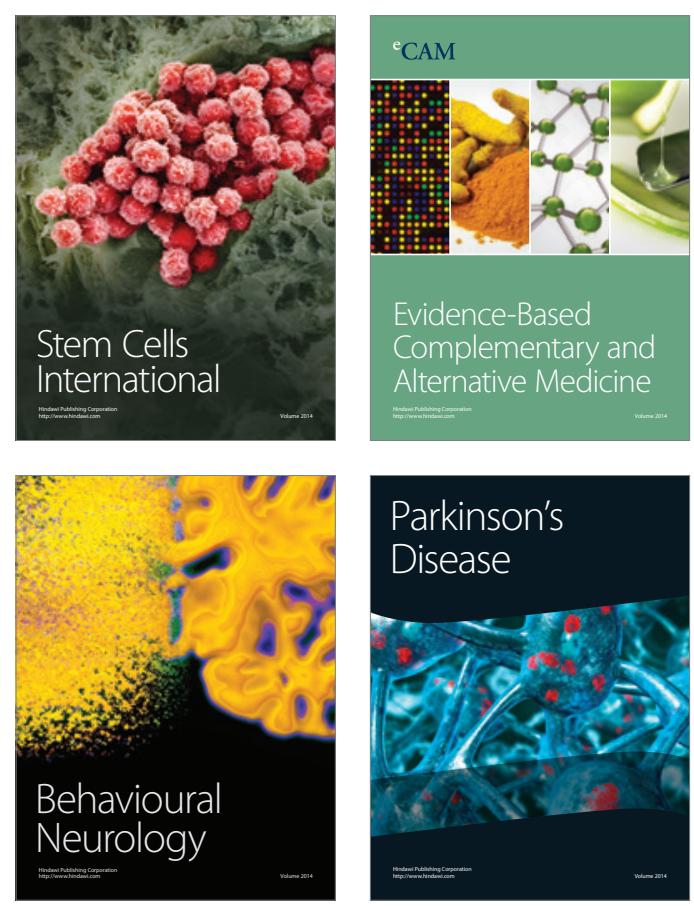

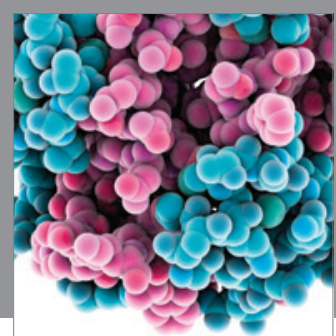

Journal of
Diabetes Research

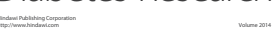

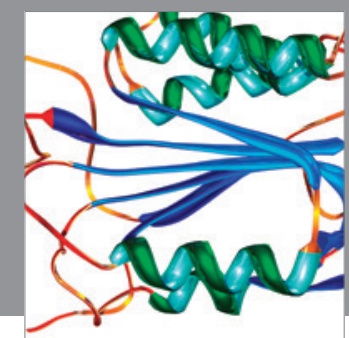

Disease Markers
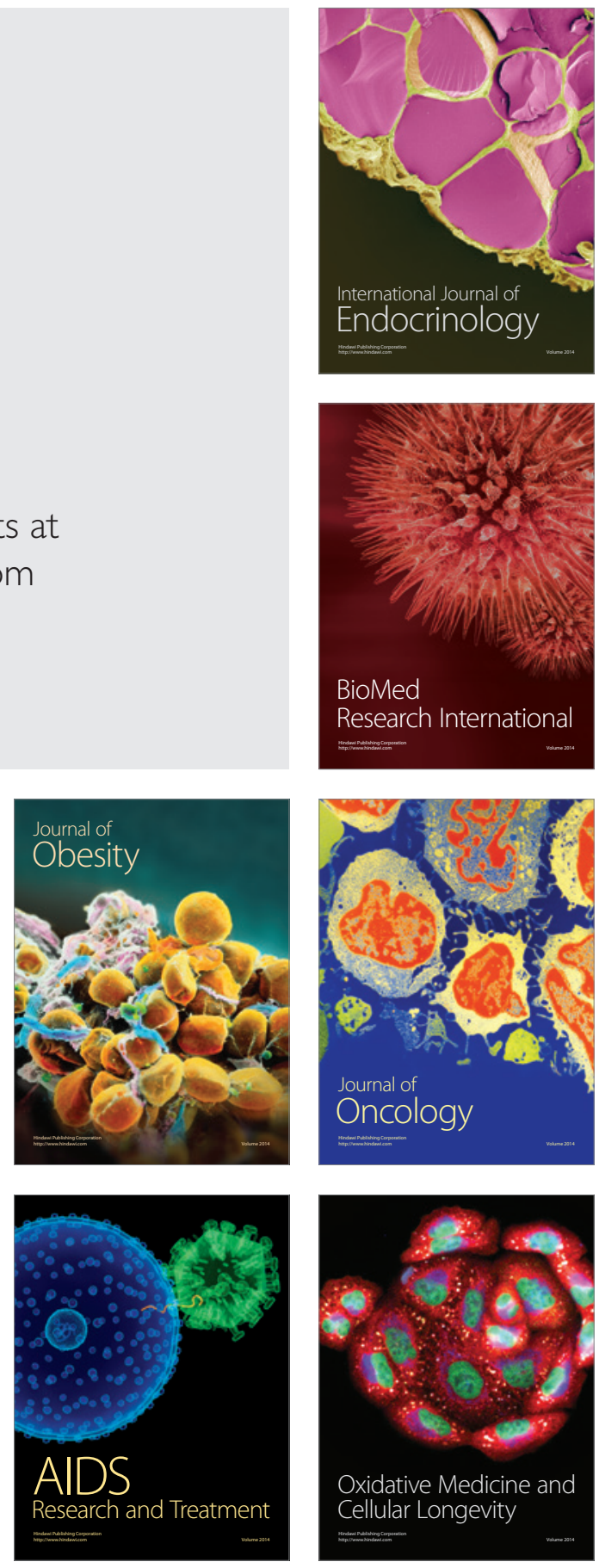